\title{
Primary Afferent-Derived BDNF Contributes Minimally to the Processing of Pain and Itch
}

\author{
Todd Dembo, ${ }^{1}$ ĐJoão M. Braz, ${ }^{1}$ Katherine A. Hamel, ${ }^{1}$ Julia A. Kuhn, ${ }^{1}$ and ${ }^{\circledR}$ Allan I. Basbaum ${ }^{1}$
}

https://doi.org/10.1523/ENEURO.0402-18.2018

${ }^{1}$ Department of Anatomy, University of California, San Francisco, San Francisco, CA 94158

\begin{abstract}
BDNF is a critical contributor to neuronal growth, development, learning, and memory. Although extensively studied in the brain, BDNF is also expressed by primary afferent sensory neurons in the peripheral nervous system. Unfortunately, anatomical and functional studies of primary afferent-derived BDNF have been limited by the availability of appropriate molecular tools. Here, we used targeted, inducible molecular approaches to characterize the expression pattern of primary afferent BDNF and the extent to which it contributes to a variety of pain and itch behaviors. Using a BDNF-LacZ reporter mouse, we found that BDNF is expressed primarily by myelinated primary afferents and has limited overlap with the major peptidergic and non-peptidergic subclasses of nociceptors and pruritoceptors. We also observed extensive neuronal, but not glial, expression in the spinal cord dorsal horn. In addition, because BDNF null mice are not viable and even Cre-mediated deletion of BDNF from sensory neurons could have developmental consequences, here we deleted BDNF selectively from sensory neurons, in the adult, using an advillin-Cre-ER line crossed to floxed BDNF mice. We found that BDNF deletion in the adult altered few itch or acute and chronic pain behaviors, beyond sexually dimorphic phenotypes in the tail immersion, histamine, and formalin tests. Based on the anatomical distribution of sensory neuron-derived BDNF and its limited contribution to pain and itch processing, we suggest that future studies of primary afferent-derived BDNF should examine behaviors evoked by activation of myelinated primary afferents.
\end{abstract}

Key words: BDNF; dorsal root ganglia; itch; neuropathic pain; spinal cord; transgenic knock-out

\section{Significance Statement}

The neurotrophin BDNF is a critical contributor to neuronal growth, development, and synaptic plasticity, and its expression in primary sensory neurons has been implicated in pain processing. However, there is little consensus as to the sensory neuron subtypes that express BDNF or whether sensory neuron-derived BDNF facilitates or inhibits pain generation. Here, we used a BDNF reporter mouse and demonstrate that BDNF predominates in myelinated sensory neurons and is expressed in many spinal cord dorsal horn neurons. In addition, in studies in which BDNF was deleted, in the adult, from all sensory neurons, we found limited deficits in pain or itch processing.

\section{Introduction}

The neurotrophin BDNF is a critical contributor to neuronal growth and development, synaptic transmission, learning, and memory (Binder and Scharfman, 2004). Al-

Received October 17, 2018; accepted November 20, 2018; First published December 13, 2018.

The authors declare no competing financial interests.

Author contributions: T.D., A.I.B., and J.M.B. designed research; T.D., K.A.H., J.M.B., and J.A.K. performed research; T.D., K.A.H., J.M.B., J.A.K., A.I.B., and J.M.B. analyzed data; T.D., A.I.B., and J.M.B. wrote the paper. though widely synthesized in the CNS (Conner et al., 1997), BDNF is also expressed in primary sensory neurons of the dorsal root ganglion (DRG; Barakat-Walter, 1996) and trigeminal ganglion (TG; Wetmore and Olson,

This work was supported by the National Institutes of Health Grant NSR35097306.

Acknowledgements: We thank Kevin Jones and Zachary Knight for providing the BDNF-LacZ reporter and floxed BDNF mice and Ardem Patapoutian for providing the Advillin-CreER mice.

Correspondence should be addressed to Allan I. Basbaum at the above 
1995). Several studies reported that BDNF is expressed in a population of small to medium-diameter DRG neurons (Michael et al., 1997; Thompson et al., 1999; Heppenstall and Lewin, 2001; Luo et al., 2001; Obata et al., 2006; Salio and Ferrini, 2016) and its expression pattern changes after nerve or tissue damage (Cho et al., 1997; Zhou et al., 1999; Fukuoka et al., 2001; Obata et al., 2006; Lin et al., 2011). For example, tissue injury increases the number of BDNF-expressing neurons in the DRG, with de novo expression in non-nociceptive, large-diameter cells and decreased expression in the small-diameter, nociceptive population. On the other hand, another report emphasized the extensive expression in presumptive proprioceptive afferents, rather than nociceptors (Betley et al., 2009). Conceivably some of the lack of agreement reflects a potential caveat of the anatomic studies, namely that because the BDNF null mutation is generally lethal (Ernfors et al., 1994) studies that characterized BDNF expression likely lacked appropriate controls for antibody and probe specificity.

The majority of studies indicate that BDNF is pronociceptive. For example, subcutaneous injection of BDNF modestly decreased heat pain threshold (Thompson et al., 1999). Intrathecal injections of BDNF or a TrkB (BDNF receptor) scavenger also decreased heat (Shu et al., 1999; Groth and Aanonsen, 2002) and mechanical thresholds (Groth and Aanonsen, 2002; Coull et al., 2005; Bao et al., 2014). Very recently (Dhandapani et al., 2018) demonstrated that TrkB-expressing sensory neurons are myelinated, low-threshold mechanoreceptors that transmit innocuous touch and their ligand-targeted photoablation reduces mechanical allodynia in a wide variety of neuropathic pain models in the mouse. Similarly, inhibiting BDNF signaling with an intrathecal antibody decreased thermal hyperalgesia in the spinal nerve ligation model of neuropathic pain (Fukuoka et al., 2001).

Taking a different approach (Zhao et al., 2006) selectively deleted BDNF from the NaV1.8 subset of sensory neurons and observed reduced nocifensive behavior after carrageenan-induced inflammation and in the second phase of the formalin test. Paradoxically, these mice were heat hypersensitive, suggesting that BDNF is antinociceptive, a result consistent with a report demonstrating GABA-mediated inhibitory effects of intrathecal BDNF (Pezet et al., 2002). In the same study, Zhao et al. (2006) found no effect on nerve injury-induced mechanical hypersensitivity. Surprisingly, the same group found opposite results, namely decreased responsiveness in a test of heat pain and reduced nerve injury generated mechanical allodynia when they deleted BDNF from sensory neurons in the adult (Sikandar et al., 2018). To address the lack of consensus, here we provide a comprehensive analysis of BDNF expression in sensory neurons and spinal cord and

address, E-mail: allan.basbaum@ucsf.edu.

https://doi.org/10.1523/ENEURO.0402-18.2018

Copyright (C) 2018 Dembo et al.

This is an open-access article distributed under the terms of the Creative Commons Attribution 4.0 International license, which permits unrestricted use, distribution and reproduction in any medium provided that the original work is properly attributed. reexamined the effect of its selective deletion from sensory neurons on both pain and itch processing. Importantly, because BDNF signaling is sexually dimorphic (Liu et al., 2012), we studied both male and female adult mice. We report that BDNF is predominantly expressed by myelinated afferents and contributes minimally to pain and itch.

\section{Materials and Methods}

\section{Animals}

Animal experiments were approved by the University of California, San Francisco Institutional Animal Care and Use Committee and were conducted in accordance with the National Institutes of Health Guide for the Care and Use of Laboratory animals. Bdnf fl/fl and Ai14 (tdTomato) reporter mice were purchased from The Jackson Laboratory. Crossing these mice resulted in double transgenic mice that provided an anatomic fate map of the expression of BDNF. Bdnf ${ }^{\mathrm{LacZ}++}$ reporter mice were kindly provided by Dr. Zachary Knight at University of California, San Francisco and Dr. Kevin Jones (Colorado; Gorski et al., 2003). This transgenic mouse expresses a knock-in floxed BDNF followed by a lacZ expression cassette. Crossing this mouse with an Advillin Cre-ERT2 line resulted in knock-out of BDNF and expression of lacZ at the BDNF locus, which leads to lacZ expression in cells that normally express BDNF in the adult. This mouse line was used for both anatomic analyses of BDNF expression (by following lacZ) and behavioral analyses of BDNF mutant mice following tamoxifen administration. The AdvillinCreERT2 mice were kindly provided by Dr. Ardem Patapoutian at the Scripps Institute.

\section{Tamoxifen-induced recombination}

Tamoxifen (Sigma) was dissolved in corn oil by vigorous vortexing for $30 \mathrm{~min}$. Cre recombination was induced by injecting animals with tamoxifen $(150 \mathrm{mg} / \mathrm{kg}$, i.p.) for five consecutive days, as described previously (Lau et al., 2011). Vehicle-treated control mice were injected with corn oil instead of tamoxifen.

\section{Behavioral analyses}

For all behavioral tests, animals were first habituated for $1 \mathrm{~h}$ in Plexiglas cylinders. The experimenter was always blind to whether the animal received tamoxifen. All mechanical (Von Frey), thermal (Hargreaves, tail immersion, hotplate, acetone), and ambulatory (rotarod) tests were conducted two weeks after the last tamoxifen injection as described previously (Cao et al., 1998; Wang et al., 2013). For the capsaicin test, capsaicin (Sigma) was first dissolved in $100 \%$ ethanol $(3.0 \mathrm{mg} / \mathrm{ml})$. This stock was mixed 1:1:8 with Tween 80 (Sigma) and saline, and injected into the hindpaw $(10 \mu l)$, with behavior then video recorded for the next $5 \mathrm{~min}$. Behavior was scored as the total duration of hindpaw licking. For the acetone test, behavior was quantified as the total duration of hindpaw lifting, licking or shaking over five consecutive, 30-s trials.

\section{Pruritogen-evoked scratching}

At least $24 \mathrm{~h}$ before testing, mice were shaved at the nape of the neck under isoflurane anesthesia. The follow- 
ing pruritogens were dissolved in saline and injected (50 $\mu$, s.c.) into the neck: chloroquine (Sigma, $100 \mu \mathrm{g}$ ), endothelin-1 (Sigma, $25 \mathrm{ng}$ ), histamine (Sigma $500 \mu \mathrm{g}$ ), SLIGRL (Sigma, $100 \mu \mathrm{g}$ ), and thymic stromal lymphopoietin (TSLP; Sigma, $2.5 \mu \mathrm{g}$ ). The mice were video recorded, and from these videos, we counted the total number of discrete scratching bouts that occurred during the first 30 min after injection.

\section{Complete Freund's adjuvant (CFA)}

The CFA model of chronic inflammation was induced as described previously (Cao et al., 1998). Briefly, CFA (Sigma) was diluted 1:1 with saline and vortexed for 30 min. When fully suspended, we injected $20 \mu$ l of CFA into one hindpaw. Heat and mechanical withdrawal thresholds were measured before the injection (baseline) and $3 \mathrm{~d}$ after using the Hargreaves and Von Frey tests, respectively.

\section{Formalin test}

The formalin test was conducted as described previously (Shields et al., 2010). Briefly, formalin was injected into the plantar surface of the hindpaw $(10 \mu \mathrm{l}, 2 \%$ in saline) and nocifensive behavior was video recorded over the following hour. The cumulative duration of all behaviors (licking, lifting, shaking, biting) was measured in 5-min bins.

To study formalin-induced Fos expression, animals were perfused $1.5-2 \mathrm{~h}$ after the formalin injection, or $48 \mathrm{~h}$ after injection to immunostain for ATF3 in the DRG. See below, Immunohistochemistry, for the list of antibodies and concentrations used. In some animals, we also studied post-formalin-induced mechanical hypersensitivity (allodynia), $1 \mathrm{~d}$ after the formalin injection (Zeitz et al., 2004).

\section{Paclitaxel model of chemotherapy-induced neuropathic pain}

Paclitaxel (Sigma) was diluted in Kolliphor EL (Sigma, $1: 1$ with $100 \%$ ethanol) to a final concentration of 6.0 $\mathrm{mg} / \mathrm{ml}$. Aliquots of $20 \mu \mathrm{l}$ were stored at $-20^{\circ} \mathrm{C}$ until use, when they were diluted $15 \times$ with saline. Mice were injected intraperitoneally with $4.0 \mathrm{mg} / \mathrm{kg}$, once per day, for five consecutive days. Heat and mechanical thresholds were measured at 12 and $13 \mathrm{~d}$, respectively, after the final injection.

\section{Spared-nerve injury (SNI) model of neuropathic pain}

The SNI model was produced as described previously (Shields et al., 2003). Briefly, under isofluroane anesthesia, two of the three branches of the sciatic nerve were ligated and transected distally, leaving the tibial nerve intact. Behavior was tested 5, 7, and $14 \mathrm{~d}$ after injury, and immunohistochemistry was performed one week after injury.

\section{Immunohistochemistry}

Tissue was immunostained as described previously (Bráz et al., 2012). Antibodies used included ATF3 (rabbit, 1:2 k, Santa Cruz Biotechnology), Fos (rabbit, 1:5 k, Oncogene), lba1 (rabbit, 1:1 k, Wako), NeuN (mouse, 1:5 k,
Sigma), $\beta$-Gal (chicken, 1:10 k, Abcam), TRPV1 (guinea pig, 1:5 k, generous gift of the David Julius lab), NF200 (mouse, 1:20 k, Sigma), CGRP (mouse, 1:10 k, Sigma), tyrosine hydroxylase (rabbit, 1:5 k, Millipore), and biotinylated IB4 (goat, 1:500, Vector Labs). Fluorescent secondary antibodies were used at a $1: 1 \mathrm{k}$ dilution; streptavidin-conjugated fluorophore was used at 1:5 k.

\section{In situ hybridization}

In situ hybridization was performed using fresh DRG tissue from adult mice (8-10-week-old), following Advanced Cell Diagnostics' protocol. DRG tissues were dissected out, instantaneously frozen on dry ice, and kept at $-80^{\circ} \mathrm{C}$ until use. DRG cryostat sections $(12 \mu \mathrm{m})$ were fixed at $4^{\circ} \mathrm{C}$ in $4 \%$ formaldehyde for $15 \mathrm{~min}$, washed twice in PBS, and dehydrated through successive ethanol steps $(50 \%, 70 \%$, and $100 \%)$ for 5 min each and dried at room temperature. After a 30-min incubation step with protease IV, sections were washed twice in PBS and incubated at $40^{\circ} \mathrm{C}$ with RNAscope-labeled probes (TRPM8, BDNF, or CGRP) for $2 \mathrm{~h}$ in a humidified chamber. Sections were then washed twice in washing buffer and incubated with four successive "signal amplifying" solutions at $40^{\circ} \mathrm{C}$, for 15-30 min each. After two washes, sections were dried and covered with mounting media containing DAPI.

\section{BDNF ELISA}

Advillin-CreERT2:Bdnf ${ }^{f l / f l}$ mice were injected with tamoxifen or vehicle (corn oil) as described above, in the section Tamoxifen-induced recombination. Two weeks after the final injection, spinal cords $(5.0 \mathrm{~mm}$ of lumbar enlargement) and TGs were homogenized in $20 \times$ volume lysis buffer ( $\mathrm{pH} 7.0)$ containing Tris- $\mathrm{HCl}(100 \mathrm{mM}), \mathrm{NaCl}$ (1.0 M), EDTA- $\mathrm{Na}_{2}(4 \mathrm{mM})$, bovine serum albumin $(2 \%)$, Triton X-100 (2\%), sodium azide (0.1\%), and complete ULTRA protease inhibitor cocktail (Roche). Homogenates were centrifuged at $14 \mathrm{k} \times g$ for $30 \mathrm{~min}$ at $4^{\circ} \mathrm{C}$. Spinal cord supernatants were diluted $10 \times$ and TG supernatants diluted $5 \times$. All supernatants were immediately assayed with the Human BDNF SimpleStep ELISA kit (Abcam). Absorbance was measured at $450 \mathrm{~nm}$ with a Biotek H4 Plate Reader.

\section{Quantitative PCR}

Tissue was homogenized in TRIzol (Ambion) and RNA was purified using the PureLink RNA Mini kit with oncolumn DNase treatment (Ambion). cDNA was prepared with the SuperScript III First-Strand Synthesis SuperMix for qRT-PCR (Invitrogen). mRNA levels were quantified with the Bio-Rad CFX Connect System using PowerUp SYBR Green Master Mix (Applied Biosystems). All transcripts were normalized to actin.

\section{Genotyping}

All genotyping parameters followed the instructions listed on The Jackson Laboratory website. The primer sets used included BDNF ${ }^{\text {LacZ/+}: ~ G G T C T G A A A T T A-~}$ CAAGCAGATGG and TGTCCGTGGACGTTTACTTCT; Advillin-CreERT2: GCGGTCTGGCAGTAAAAACTATC and GTGAAACAGCATTGCTGTCACTT; BDNF ${ }^{\text {flff: }}$ : TGTGATT- 
GTGTTTCTGGTGAC and GCCTTCATGCAACCGAAGTATG.

\section{Imaging}

All images were taken on an LSM 700 confocal microscope (Zeiss) equipped with 405-nm (5-mW fiber output), 488-nm (10-mW fiber output), 555-nm (10-mW fiber output), and 639-nm (5-mW fiber output) diode lasers using a $20 \times$ Plan-Apochromat $(20 \times / 0.8)$ objective (Zeiss). Image acquisition was done with ZEN 2010 (Zeiss). Image dimensions were $1024 \times 1024$ pixels with an image depth of 12 bits. Two-times averaging was applied during image acquisition. Laser power and gain were adjusted to avoid saturation of single pixels. Adjustment of brightness/contrast and changing of artificial colors (LUT) were done in Fiji/ImageJ. The same imaging parameters and adjustments were used for all images within an experiment.

\section{Experimental design and statistical analysis}

For cell counting of DRG neurons, we collected $12-\mu \mathrm{m}$ cryosections of L4/5 DRGs from at least three animals per group. The sections were directly mounted on Superfrost microslides. To avoid double counting of the same cell, we mounted, immunostained, and counted neurons in every fifth section of each ganglion. ATF3-immunoreactive neurons were identified using the particle analyzer function in ImageJ. To quantify the percentage of $\beta$-Gal-immunoreactive (BDNFexpressing) DRG neurons that coexpressed NF200, peripherin, CGRP, TRPV1, IB4, or TH, we counted at least $100 \beta$-Galpositive neurons for each mouse and calculated the percentage of double-labeled neurons ( $\beta$-Gal/neuronal marker).

All behavioral studies were performed blind to treatment (e.g., tamoxifen vs corn oil). Mice were randomly assigned to experimental groups with eight to nine mice per group, a number based on our previous and other studies using comparable tests. Importantly, in the different behavioral experiments, the mice served as their own controls. Data were collected before and after tamoxifeninduced deletion of BDNF. In one experiment, postformalin-induced mechanical hypersensitivity, only six mice per group were studied. When results from male and female mice did not differ, the results were combined.

\section{Statistical analyses}

All statistical analyses were performed with Prism (GraphPad). Anatomic and behavioral data are reported as mean \pm SEM. In all experiments where males and females were compared, two-way ANOVA was used first (with Bonferroni correction for multiple comparisons) to determine whether any of the mean endpoints were significantly different between sex and genotype. If differences were found, males and females were compared separately in the final analysis using two-way ANOVA with Bonferroni correction. If no differences were found, male and female data were grouped together and the pooled endpoints were compared using $t$ tests or ANOVA. Specifically, if pooled endpoints were independent from one another (e.g., when comparing the effects of different pruritogens or looking at phases of the formalin test), multiple $t$ tests were used with Bonferroni correction for multiple comparisons. When endpoints were not indepen- dent (e.g., in the hotplate test), ANOVA was used with Bonferroni correction for multiple comparisons.

\section{Results}

\section{Anatomic characterization of BDNF ${ }^{\mathrm{LacZ} /+}$ mice}

Previous attempts to characterize the expression of BDNF in primary afferent neurons relied on immunohistochemistry or in situ hybridization. However, BDNF antibodies are known to be problematic, and in situ studies, although more reliable, were not comprehensive. Because of the importance of relating expression patterns to sensory neuron subpopulations, here we took advantage of a knock-in reporter animal that expresses $\beta$-Gal under control of the BDNF promoter. This $B D N F^{L a c Z /+}$ animal has previously been used to characterize BDNF expression in the brain (Xu et al., 2003), but to our knowledge, this is the first analysis in sensory neurons or spinal cord.

Our investigation focused on DRGs $L 4 / 5$, as these levels innervate the plantar surface of the hindpaw, where most of our behavioral experiments were conducted. Figure 1 illustrates that the intensity of $\beta$-Gal immunoreactivity within DRG neurons varied considerably. Immunolabeling in highexpressing cells $(\sim 32.3 \pm 4.5 \%$ of total BDNF+ neurons; $N$ $=5)$ completely filled both the nucleus and cytoplasm. Medium-expressing cells were characterized by punctate staining of the nucleus and cytoplasm. Low-expressing cells had punctate staining in the cytoplasm and little to no nuclear labeling (medium-to-low expressing cells: $\sim 67.8 \pm$ $4.6 \%$ of total BDNF+ neurons; $N=5$; Fig. $1 A$ ). For the purposes of this investigation, all $\beta$-Gal-positive cells were treated equally, regardless of staining intensity. Importantly, because the $\beta$-Gal reporter animal is not a fusion construct between LacZ and BDNF, the $\beta$-Gal pattern defines the neurons that express BDNF, rather than the intracellular staining pattern of BDNF itself. Cell counts showed that there are $\sim 200 \beta$-Gal-positive neurons per DRG, with similar numbers in male and female mice (Fig. 1B).

We next characterized $\beta$-Gal-positive cells with a panel of markers that distinguish subpopulations of DRG neurons (Fig. $1 C-l)$. The majority of the $\beta$-Gal neurons ( $67 \%)$ coexpressed NF200 (Fig. 1D), a marker of myelinated afferents; $\sim 12 \%$ expressed peripherin, a marker of most unmyelinated $C$ fibers (Fig. 1E). The relative abundance in myelinated afferents is consistent with an earlier report, using a BDNF-LacZ knock-in mouse, that at least $80 \%$ of proprioceptive neurons express BDNF (Betley et al., 2009). A small percentage of the BDNF neurons coexpressed TRPV1 ( 14\%; Fig. 1F) or CGRP ( 20\%; Figs. $1 G, 2 B-D$ ), markers of small, peptidergic nociceptive fibers and some A $\delta$ afferents. Only $\sim 7 \%$ of the lacZpositive neurons bound IB4 (Fig. $1 H$ ), which marks small, non-peptidergic, nociceptive afferents. Finally, we rarely detected $\beta$-Gal-positive neurons that coexpressed tyrosine hydroxylase ( $\mathrm{TH} ; \sim 0.5 \%$; Fig. $1 /)$, a marker of small, unmyelinated, low-threshold mechanoreceptive afferents (CLTMs). By in situ hybridization, we found that $\sim 23 \%$ of the BDNF mRNA-expressing sensory neurons coexpressed the menthol receptor TRPM8 (Fig. 2), a marker of small, cold-responsive cells. These cells are largely non- 


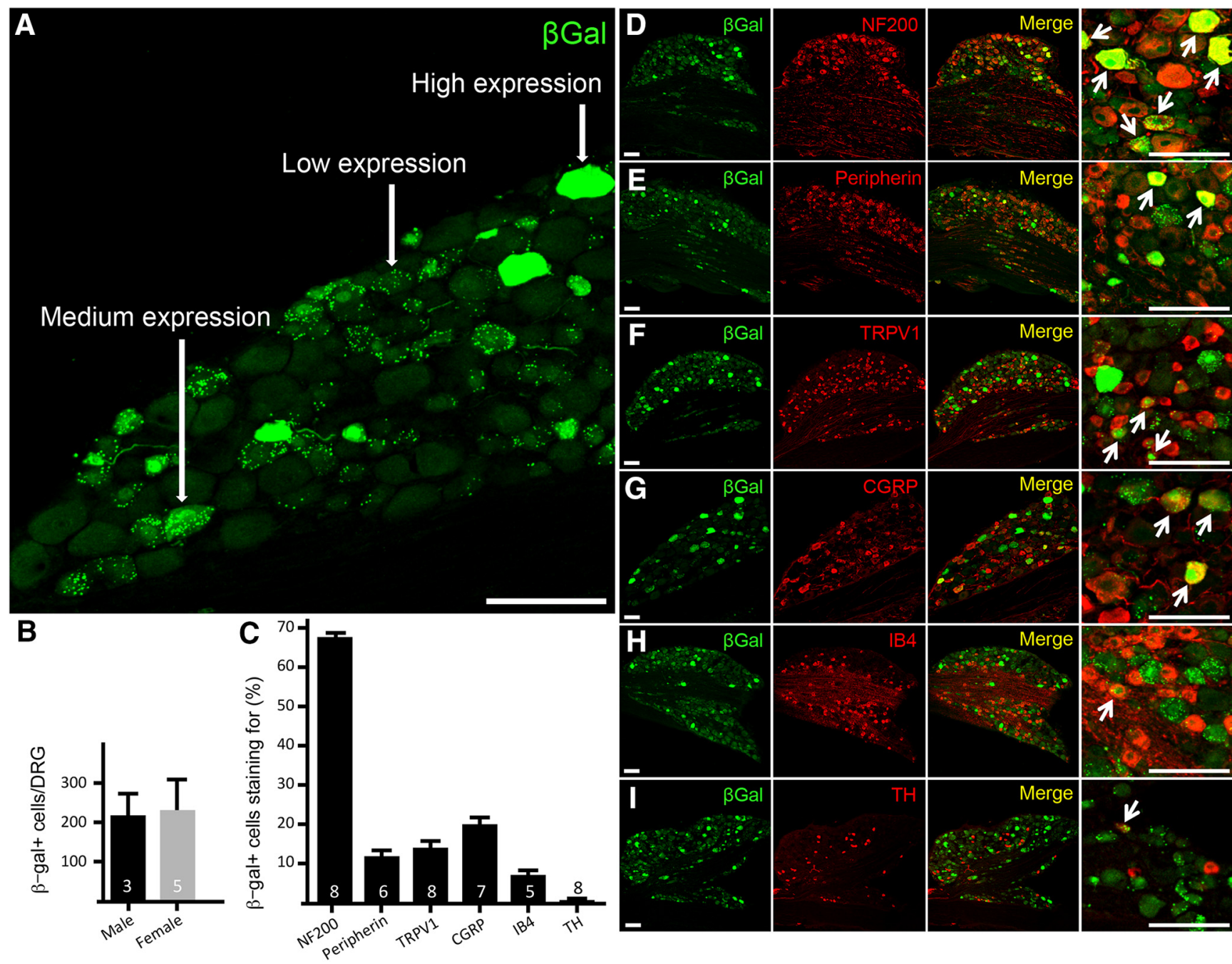

Figure 1. BDNF expression in the DRG of the BDNF-LacZ knock-in reporter mouse. $\boldsymbol{A}, \beta$-Gal expression was found in a heterogeneous population of primary afferent neurons. Levels of expression varied, with some cells completely filled by $\beta$-Gal (high expression), others with punctate nuclear and cytoplasmic staining (medium expression), and some with only punctate cytoplasmic staining (low expression). B. The number of $\beta$-Gal-positive DRG cells did not differ in male and female mice. $\boldsymbol{C}$, By counterstaining with a panel of markers of subpopulations of DRG neurons, we determined that $\sim 67 \%$ of BDNF-expressing neurons express NF200 $(\boldsymbol{D})$, a marker of myelinated fibers. Only $\sim 12 \%$ of BDNF cells expressed peripherin $(\boldsymbol{E})$, a marker of most small-diameter afferents. Similarly, only $\sim 14 \%$ of BDNF-positive afferent expressed TRPV1 (F) and $\sim 20 \%$ expressed CGRP (G), markers of small-diameter, peptidergic nociceptors. $\boldsymbol{H}$, IB4, a lectin that binds small, non-peptidergic nociceptors, was only found in $\sim 10 \%$ of BDNF neurons. Finally, there was virtually no overlap $(\sim 0.5 \%)$ with $\mathrm{TH}(\boldsymbol{I})$, a marker of small-diameter, low-threshold, mechanosensory afferents. Data are mean \pm SEM. Statistical significance was determined by Student's $t$ test. Arrows indicate cells with overlap of $\beta$-Gal with other markers. Numbers of animals are indicated in $\boldsymbol{B}, \boldsymbol{C}$. Scale bars $=100 \mu \mathrm{m}$.

overlapping with those that express peripherin, TRPV1, CGRP, or IB4 (Dhaka et al., 2008; Takashima et al., 2010).

In parallel studies, we crossed mice that express Cre recombinase under control of the BDNF promoter, with Ai14 (tdTomato-expressing) reporter mice. Compared to the number of $\beta$-Gal-positive neurons in the adult, the tdTomato expression showed that BDNF is expressed in a much larger number of sensory neurons (Fig. 3A-E). This finding reflects the fact that this approach provides a fate map of all neurons that express BDNF, from the embryo through the adult. We also recorded a large number of spinal cord neurons in dorsal horn laminae I-V (Fig. $3 F-H)$. On the other hand, we never found BDNF in nonneuronal cells in either the DRG (e.g., satellite cells or macrophages; Fig. $3 A, B)$ or in the spinal cord, e.g., microglia (Fig. 3G) and astrocytes (Fig. $3 H$ ). Because the tdTomato fate map in spinal cord neurons may have resulted only from embryonic Cre recombination, we also examined BDNF expression in adult spinal cord by in situ hybridization. Figure 4 illustrates that BDNF is indeed expressed in spinal cord neurons in adult mice.

\section{Conditional, primary afferent-driven deletion of BDNF}

To address concerns about the effect of developmental BDNF deletion (i.e., using a Cre line that expresses in the embryo), here we took advantage of an inducible AdvillinCreERT2, which is expressed in $>90 \%$ all primary affer- 

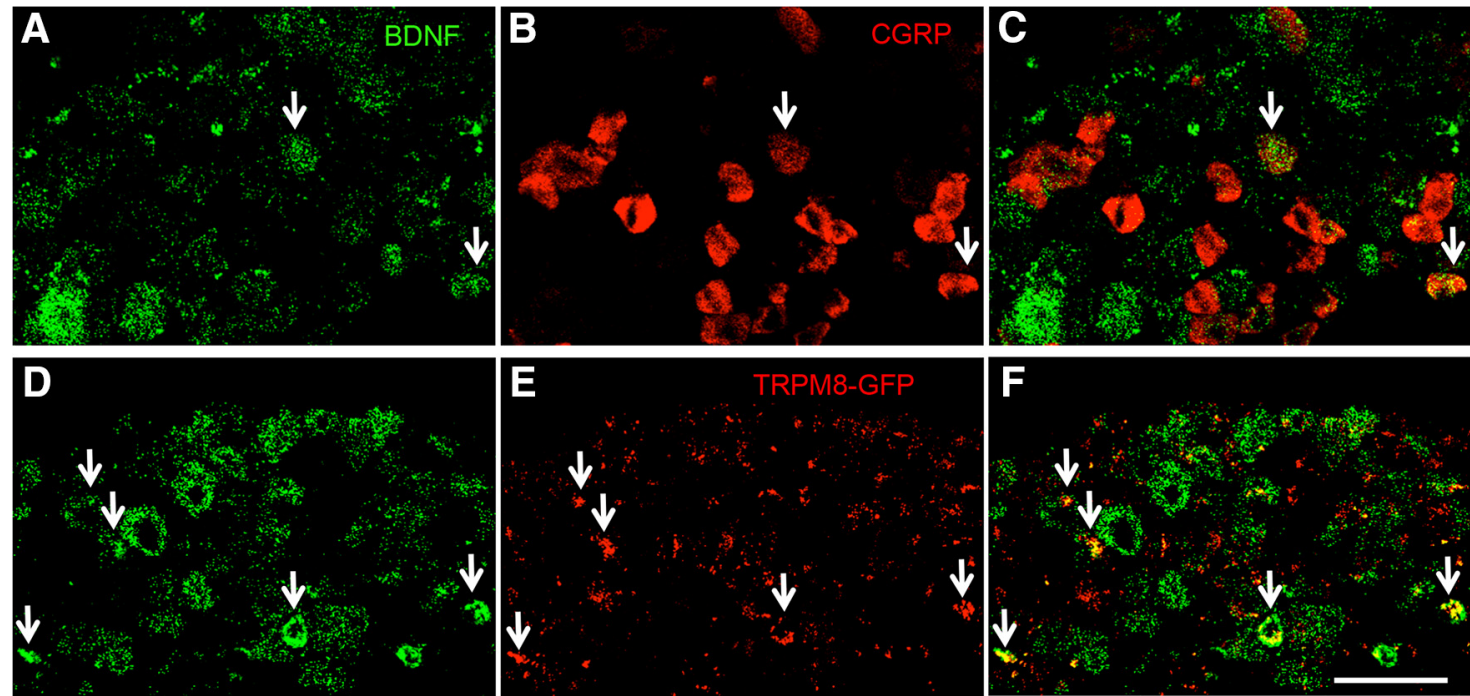

$\mathbf{E}$
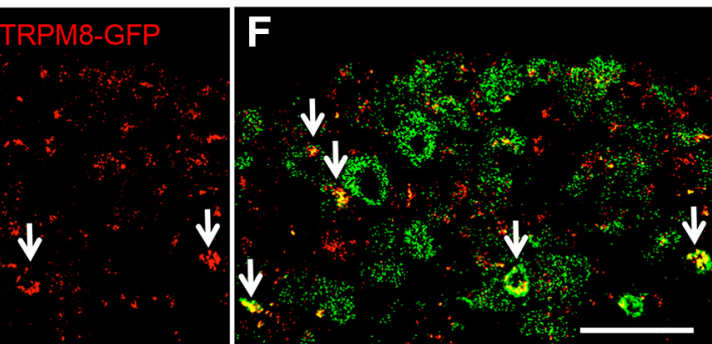

Figure 2. Coexpression of BDNF with the neuropeptide CGRP or the cold receptor, TRPM8. A, Double in situ hybridization confirmed that some BDNF mRNA-positive neurons (green in $\boldsymbol{A}, \boldsymbol{D}$ ), coexpress CGRP (red in $\boldsymbol{B}, \boldsymbol{C}$ ). $\boldsymbol{D}-\boldsymbol{F}$, Double in situ hybridization for GFP (red in $\boldsymbol{E}, \boldsymbol{F}$ ) and BDNF (green in $\boldsymbol{D}$ ) in DRG neurons from TRPM8-GFP knock-in mice show that $\sim 23 \%$ of BDNF-positive neurons coexpress TRPM8. Scale bar $=100 \mu \mathrm{m}$.
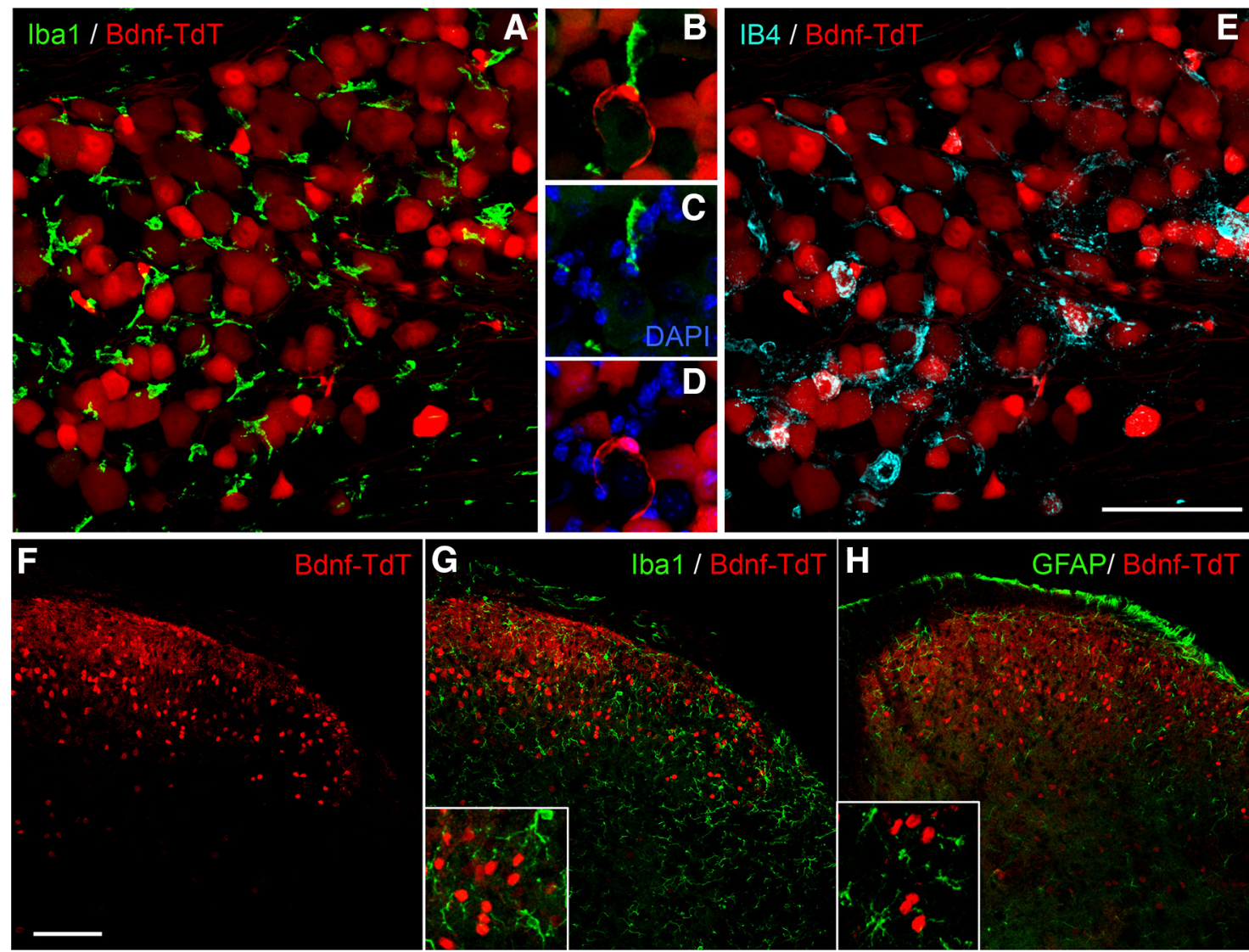

Figure 3. Fate map of BDNF expression in sensory ganglia and spinal cord neurons $\boldsymbol{A}-\boldsymbol{E}$, In double transgenic BDNF-Cre/floxedtdTomato mice, tdTomato (red) was recorded in a large number of DRG neurons, but not in macrophages, identified by expression of lba1 (green in $\boldsymbol{A}, \boldsymbol{B}$ ). A wide variety of DRG neurons expressed tdTomato, some of which were marked by IB4 binding (blue in $\boldsymbol{E}$ ). Insets $\boldsymbol{B}-\boldsymbol{D}$ show high magnifications of cells from $\boldsymbol{A}$. $\boldsymbol{F}-\boldsymbol{H}$, TdTomato (red) was also expressed in spinal cord neurons, but not in microglia (Iba1+, green in $\mathbf{G}$ ) or astrocytes (GFAP+, green in $\boldsymbol{H}$ ). Insets show high magnification of labeled cells. Scale bars $=100$ $\mu \mathrm{m}$. 

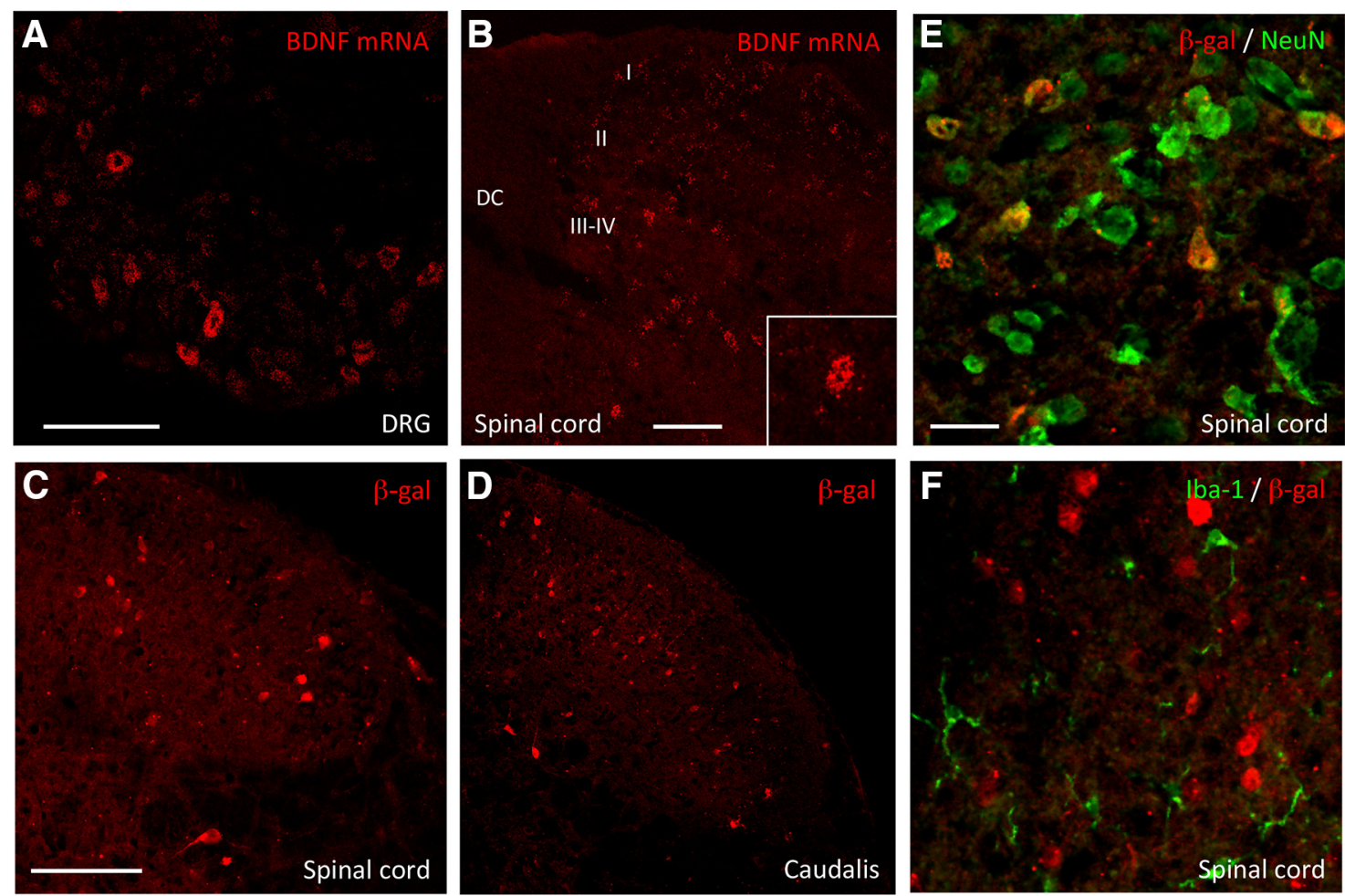

Figure 4. BDNF expression in sensory ganglia and spinal cord neurons of the adult mouse. $\boldsymbol{A}, \boldsymbol{B}$, mRNA expression of BDNF in adult DRG $(\boldsymbol{A})$ and spinal cord $(\boldsymbol{B})$ neurons revealed by in situ hybridization. BDNF mRNA was detected in all laminae of the dorsal horn. $\boldsymbol{C}-\boldsymbol{F}$, In the adult BDNF-LacZ knock-in reporter mice, $\beta$-Gal expression was also found in spinal cord $(\boldsymbol{C})$ and trigeminal nucleus caudalis neurons $(\boldsymbol{D})$. We only recorded $\beta$-Gal expression in neurons (NeuN+, green in $\boldsymbol{E}$ ), not in microglia (Iba1+, green in $\boldsymbol{F}$ ). Scale bars $=100 \mu \mathrm{m}(\boldsymbol{A}, \boldsymbol{B}, \boldsymbol{D}-\boldsymbol{F})$ and $25 \mu \mathrm{m}(\boldsymbol{C})$. DC: dorsal column; I, II, III-IV: laminae I, II and III-IV.

ents (Lau et al., 2011). Crossing these mice with a floxedBDNF line and treating adult mice with tamoxifen, generates a conditional knock-out (cKO) mouse. Although a previous report using this mouse found no difference in the number of neurons in the DRG after deletion (Zhao et al., 2006), those authors did not quantify the magnitude of the BDNF deletion in the DRG. Here, using qPCR, we found there was an almost complete deletion of BDNF mRNA from DRG and TG neurons ( 96\% and $\sim 91 \%$, respectively; Fig. 5A). A BDNF ELISA further demonstrated that BDNF protein levels in the TG dropped below the detection limit of the assay (Fig. 5B). Importantly, BDNF protein levels were unchanged in the spinal cord, which indicates, as expected, that Advillin-CreERT2 does not drive recombination in spinal cord neurons. This conclusion was confirmed in the Advillin-CreERT2-dependent tdTomato reporter animals, in which we only detected tdTomato in presumptive primary afferent terminals in spinal dorsal horn (Fig. 5C). We conclude that the BDNF knock-out was restricted to primary afferent sensory neurons.

\section{Baseline tests of pain and itch processing}

The conditional BDNF knock-out (cKO) mice responded normally on the rotarod test (Fig. 6A), which demonstrates that there were no significant motor abnormalities that could compromise tests that assayed hindlimb withdrawal. This finding also suggests that the expression of BDNF in proprioceptive afferents (Betley et al., 2009) is not required for normal proprioception. Mice also responded normally in the Von Frey test, which measures mechanical sensitivity (Fig. 6B). BDNF CKO and vehicletreated control mice also did not differ in nociceptive tests of thermal sensation, including the hotplate (Fig. 6C) and Hargreaves tests (Fig. 6E) for heat, and the acetone test of cold sensitivity (Fig. 6G). Chemonociception, in response to hindpaw injection of capsaicin, was also unchanged in the cKO mice (Fig. 6F). Surprisingly, the BDNF cKO mice showed a sexually dimorphic phenotype in the tail immersion test of heat sensitivity at $49^{\circ} \mathrm{C}$; male, but not female, knock-out mice had increased withdrawal latencies (Fig. $6 D$ ). Finally, scratching in response to most of the tested pruritogens did not differ (Fig. 7A) between wild-type and cKO mice, with the exception of histamine (Fig. 7B), where we found that tamoxifen treatment (i.e., BDNF deletion) significantly reduced histamine-induced scratching, but only in female mice. However, as baseline scratching was significantly greater in female than male mice, the BDNF deletion actually normalized responsiveness in the female mice.

\section{Sexually dimorphic, reduced responsiveness in the formalin test of inflammatory pain}

The formalin test is a model of persistent inflammation and considered to be a reliable correlate of tissue injuryinduced pain. As noted above the previous studies (using NaV1.8-Cre or advillin-Cre-ER-mediated deletion of BDNF) found reduced responsiveness in the second 
A

BDNF mRNA
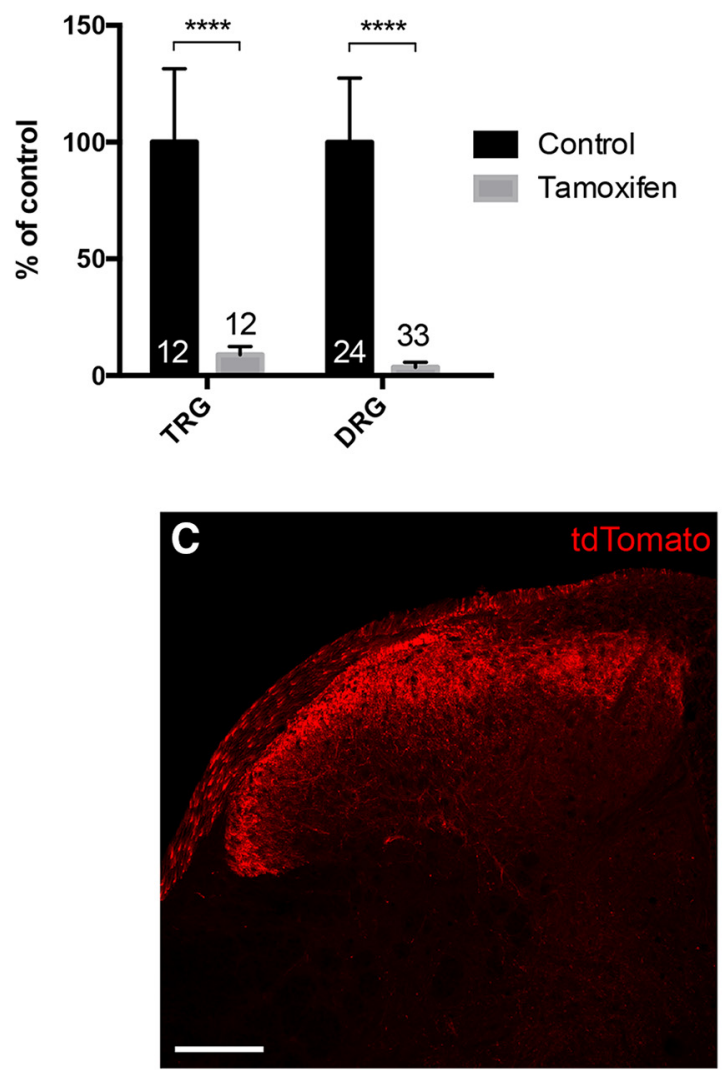

B

BDNF Protein
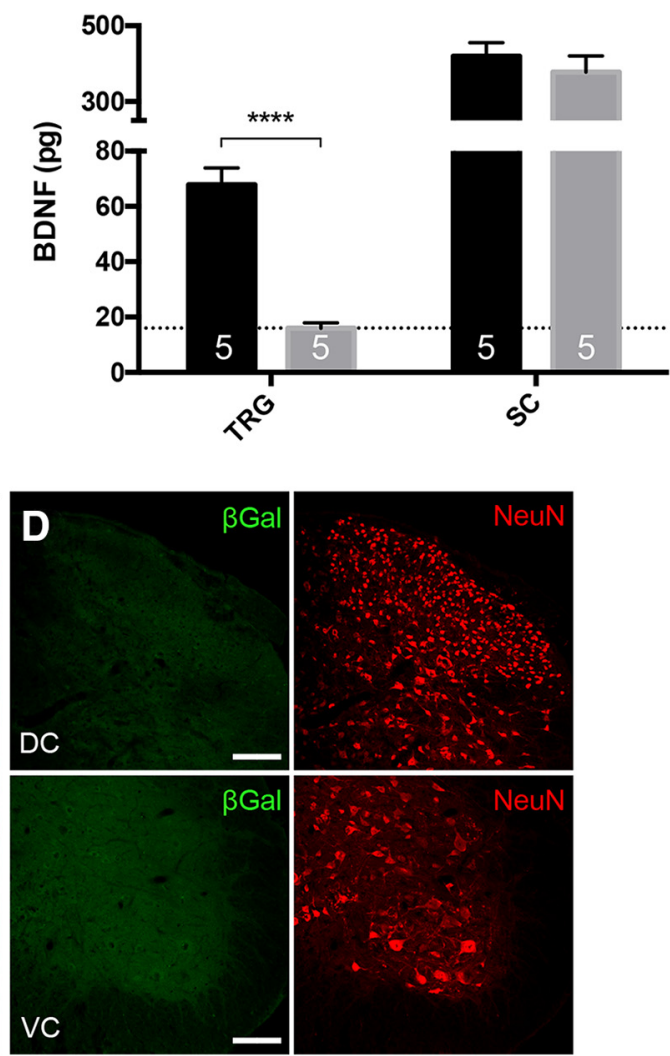

Figure 5. Advillin-CreERT2-mediated primary afferent deletion of BDNF. A, Compared to control animals treated with vehicle, qRT-PCR of DRG and trigeminal ganglia (TRG) showed highly significant depletion of BDNF ( $91 \%$ and $\sim 97 \%$, respectively) after tamoxifen-induced Cre recombination. $\boldsymbol{B}$, ELISA showed that BDNF peptide was reduced in the TRG, but not spinal cord (SC). The dotted line indicates the detection limit of the ELISA; values below this line were statistically indistinguishable from zero. $\boldsymbol{C}$, Consistent with the qPCR and ELISA findings, after crossing Advillin-CreERT2 animals with a tdTomato reporter line and treating with tamoxifen, we only detected tdTomato in presumptive primary afferent terminals of the spinal cord dorsal horn. $\boldsymbol{D}$, Furthermore, double transgenic Advillin-CreERT2/floxed-LacZ mice did not exhibit any $\beta$-Gal staining in the spinal cord after tamoxifen. Together, these results indicate that Advillin-CreERT2 does not drive Cre expression in the spinal cord, the neurons of which are indicated by NeuN immunostaining (red in $\boldsymbol{D}$ ) and that tamoxifen-induced recombination is selective for sensory ganglia. Data are mean \pm SEM. Statistical significance was determined by multiple $t$ tests with Bonferroni correction for multiple comparisons; $* * p<0.01, * * * * p<$ 0.0001. Numbers of animals are indicated in $\boldsymbol{A}, \boldsymbol{B}$. Scale bars $=100 \mu \mathrm{m}$. DC: dorsal cord; VC: ventral cord.

phase of the formalin test, which lasts from $\sim 15-50$ min after the formalin injection (Zhao et al., 2006). Interestingly, we found that male, but not female mice, showed dramatic reductions in their responses during the second phase of the test (Fig. 7C,D). This result was unexpected as the first (NaV1.8) study of Zhao et al. (2006) only used female mice and recorded decreased second phase formalin behavior. As their subsequent study intermingled male and female mice, we cannot determine whether their findings are consistent with our current findings.

Some studies suggest that the second phase of the formalin test is a manifestation of central sensitization of dorsal horn nociceptive circuits that is driven by activity during the first phase (however, see Taylor et al., 1997; Shields et al., 2010). As central sensitization is also presumed to underlie post-formalin secondary hyperalgesia, in which there is mechanical hypersensitivity of intact regions near the inflamed hindpaw, we also examined post-formalin, mechanical thresholds in male animals, $1 \mathrm{~d}$ after the formalin injection (Zeitz et al., 2004). Figure $7 E$ shows that, in fact, BDNF cKO mice displayed the same degree of mechanical hypersensitivity as control mice. In addition, spinal cord Fos expression, a marker of neuronal activity (Fig. $8 A, B$ ), and primary afferent expression of ATF3 (Fig. $8 C, D$ ), a marker of peripheral nerve injury, did not differ between control and BDNF cKO mice. We conclude that deletion of BDNF in the adult has limited influence on a variety of acute pain and itch behaviors.

\section{Primary afferent-derived BDNF does not contribute to persistent pain}

Here, we examined the consequence of deleting BDNF in various models of chronic neuropathic and inflammatory pain. We expected that the behavior of BDNF cKO animals would recapitulate previous findings that showed that inhibiting TrkB signaling reduces hyperalgesia and allodynia in multiple models of chronic pain (Fukuoka et al., 2001; Wang et al., 2009; Bao et al., 2014). We were 


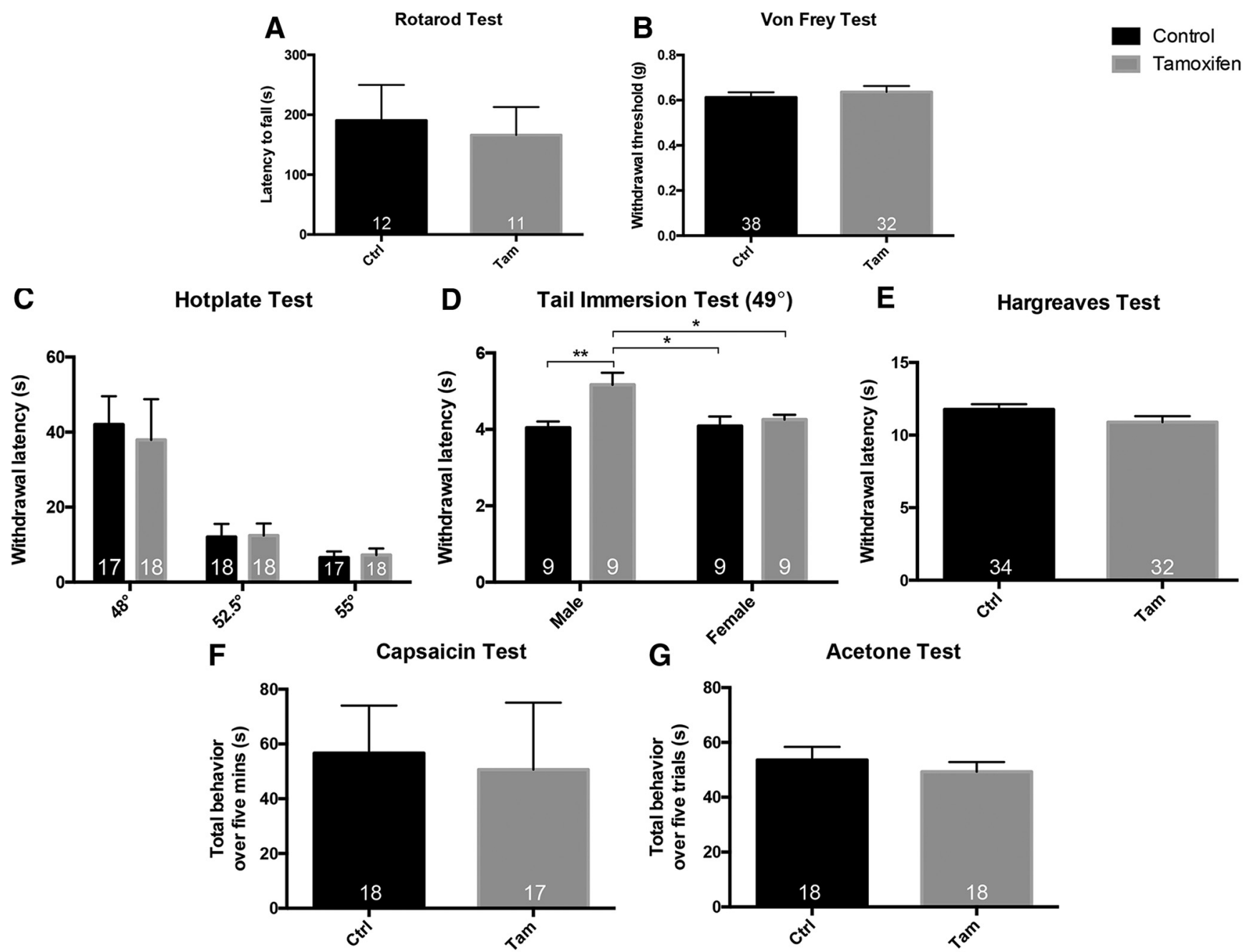

Figure 6. Baseline nociceptive responsiveness of the BDNF-cKO mice $\boldsymbol{A}, \boldsymbol{B}$, BDNF cKO mice (Tam; gray) displayed normal behavior compared to vehicle-injected controls (Ctrl) on the rotarod test $(\boldsymbol{A})$ of motor behavior and Von Frey test $(\boldsymbol{B})$ of mechanical thresholds. $\boldsymbol{C}$, Tamoxifen-treated cKO mice also responded normally on the hotplate test at all tested temperatures. $\boldsymbol{D}$, Male knock-out mice showed a significant hyposensitivity in the tail immersion test compared to all other groups. As all knock-out mice responded normally in the Hargreaves $(\boldsymbol{E})$, capsaicin $(\boldsymbol{F})$, and acetone $(\boldsymbol{G})$ tests results from male and female were combined. Numbers of animals are indicated on graphs. Data are mean \pm SEM. For $\boldsymbol{A}, \boldsymbol{B}, \boldsymbol{E}-\mathbf{G}$, statistical significance was determined by Student's $t$ test. For $\boldsymbol{C}$, statistical significance was determined by ANOVA with Bonferroni correction for multiple comparisons. For $\boldsymbol{D}$, statistical significance was determined by two-way ANOVA with Bonferroni correction for multiple comparisons; $* p<0.05, * * p<0.01$.

surprised, therefore, to find that knock-out animals developed normal mechanical hypersensitivity in the SNI model of neuropathic pain (Fig. 9A). The hypersensitivity lasted throughout the 14-d test period. The knock-out and wildtype animals also developed comparable levels of mechanical hypersensitivity in the Paclitaxel model of chemotherapy-induced neuropathic pain (Fig. 9B,C). Finally, the BDNF cKO and control mice developed comparable mechanical and thermal (heat) hypersensitivity $3 \mathrm{~d}$ after injection of CFA (Fig. 9D,E), which generates a model of tissue injury-induced chronic inflammation.

\section{Discussion}

In this study, we characterized the expression of primary afferent-derived BDNF, as well as its contribution to the processing of pain and itch-inducing messages. In distinct contrast to previous reports, we found that BDNF is expressed primarily by myelinated neurons, with a much smaller percentage of BDNF-positive neurons coexpressing the peptidergic marker CGRP. We next used a tamoxifen-inducible, primary afferent-specific Cre recombinase to delete BDNF selectively from adult, sensory neurons. This approach avoided the inevitable concern that because of its extensive expression in DRG and spinal cord during embryonic development, deletion of BDNF could produce changes that complicate the interpretation of BDNF phenotypes in the adult. With few exceptions, BDNF deletion did not alter pain- or itchassociated behaviors. We did observe that male knockout animals were less responsive in the tail immersion and formalin tests, while the scratching induced by histamine was only affected (reduced) in female mice. Perhaps most surprisingly, despite ample evidence showing that BDNF 
A

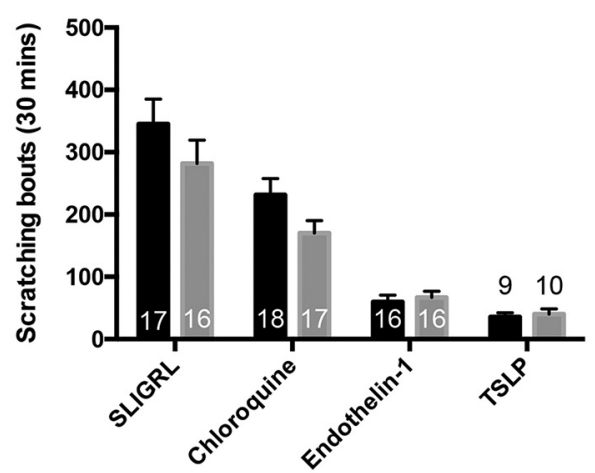

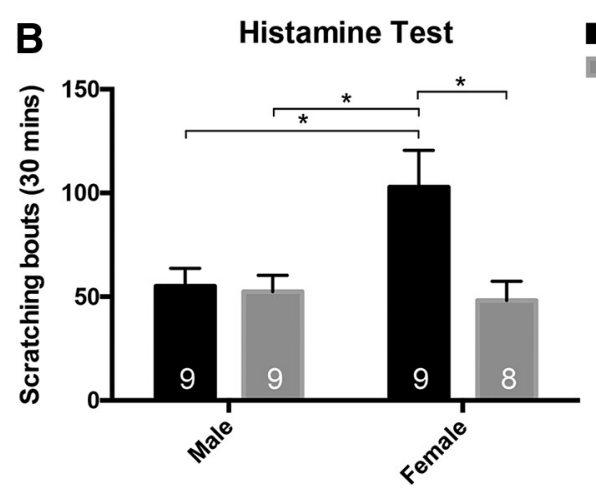

Control

Tamoxifen
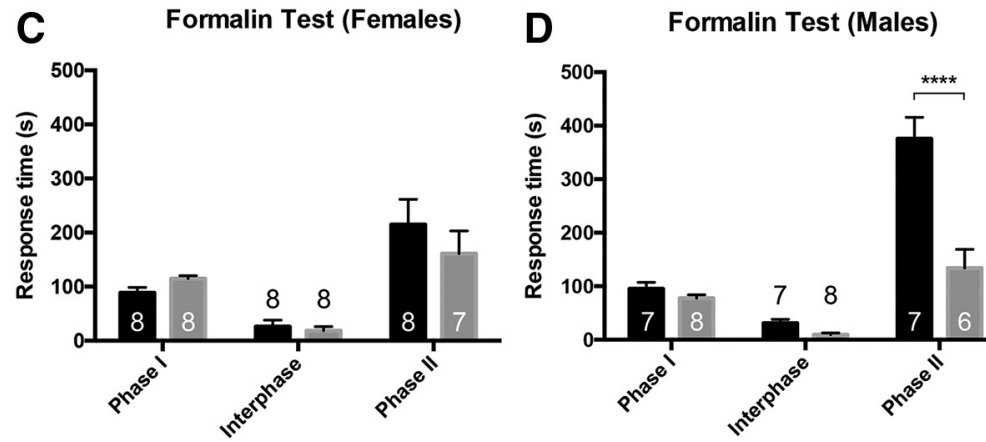

E Allodynia 1 Day after Formalin (Males)

Figure 7. Pruritogen and formalin responsiveness in BDNF-cKO mice. $\boldsymbol{A}$, Tamoxifen-treated cKO mice responded normally to injections of acute pruritogens including SLIGRL, chloroquine, endothelin-1, and TSLP. $\boldsymbol{B}$, Female mice showed statistically elevated responses to histamine compared to vehicle-injected control animals, but the increase disappeared after tamoxifen, i.e., after BDNF deletion. $\boldsymbol{C}$, Female tamoxifen-treated cKO mice did not respond differently from corn oil-injected controls during any of the three phases of the formalin test. $\boldsymbol{D}$, Male BDNF cKO mice showed a large, highly significant decrease in their responses, but only during the second phase of the formalin test. $\boldsymbol{E}$, Despite the dramatic reduction in behavior during the second phase of the formalin test, male cKO mice nevertheless developed significant mechanical allodynia $24 \mathrm{~h}$ after the formalin injection equivalent to that recorded in the control mice. Data are mean \pm SEM. For $\boldsymbol{A}, \boldsymbol{C}, \boldsymbol{D}$, statistical significance was determined by multiple $t$ tests with Bonferroni correction for multiple comparisons. For $\boldsymbol{B}$, statistical significance was determined by two-way ANOVA with Bonferroni correction for multiple comparisons. For $\boldsymbol{E}$, statistical significance was determined by Student's $t$ test; $* p<0.05, * * * * p<0.0001$. Numbers of animals are indicated on graphs.

expression changes dynamically in the setting of nerve injury (Cho et al., 1997; Zhou et al., 1999; Fukuoka et al., 2001; Obata et al., 2006; Lin et al., 2011; Cao et al., 2012), the BDNF knock-out animals developed normal mechanical and thermal hypersensitivity in several models of neuropathic and chronic inflammatory pain. Based on these findings, we conclude that sensory neuron-derived BDNF is not a necessary or significant contributor to acute pain or itch processing, or to the development of neuropathic or chronic inflammatory pain. Whether BDNF contributes to ongoing pain should be determined in future studies. Our findings contrast significantly with several previous reports (see below).

A major distinction between our anatomic analysis and previous studies of BDNF expression in sensory neurons is that we did not rely on BDNF antibodies. Because the BDNF null mutation is lethal (Ernfors et al., 1994), it is difficult to verify BDNF antibody. By using a Credependent, knock-in reporter construct that drives $\beta$-Gal expression selectively in adult animals (Gorski et al., 2003), the analysis performed in the present report obviated this concern. Interestingly, although we found that diverse populations of sensory neurons express BDNF, myelinated afferents predominated, a finding at odds with earlier reports concluding that BDNF is expressed mainly in unmyelinated nociceptors (Michael et al., 1997; Thompson et al., 1999; Heppenstall and Lewin, 2001; Luo et al., 2001; Obata et al., 2006; Salio and Ferrini, 2016). Because TRPM8, peripherin, and NF200 largely label nonoverlapping populations in the mouse (Dhaka et al., 2008; Takashima et al., 2010) and, together, account for the majority of DRG neurons, we conclude that our analysis characterized almost the entire population of BDNF neurons (NF200 $=\sim 67 \%$ overlap, peripherin $=\sim 12 \%$ overlap, and TRPM $8=\sim 23 \%$ overlap).

Of particular note are the significant discrepancies between our results and those of Zhao et al. (2006), who deleted BDNF from sensory neurons using an NaV1.8-Cre cross. The authors reported hotplate hypersensitivity and formalin hyposensitivity in female mice after developmental BDNF deletion and no change in mechanical thresholds in a nerve injury induced model of neuropathic pain. Male mice were not tested in that study. However, when those authors selectively deleted BDNF in adult mice 

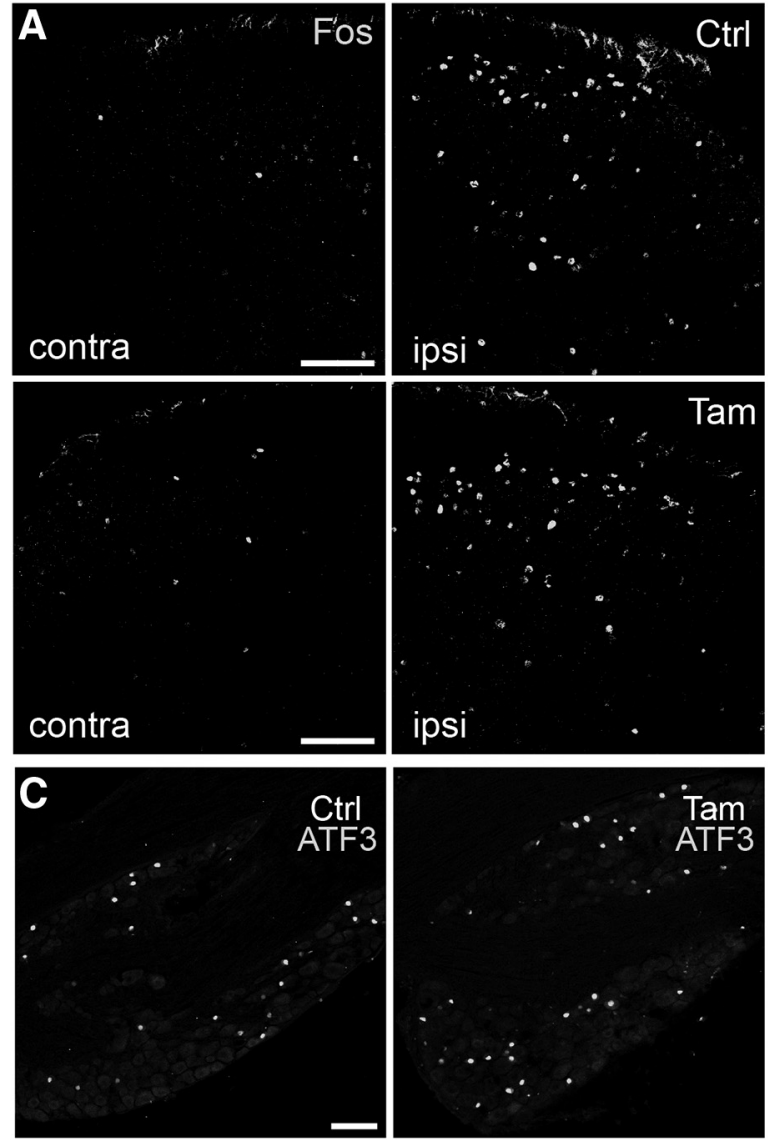

B
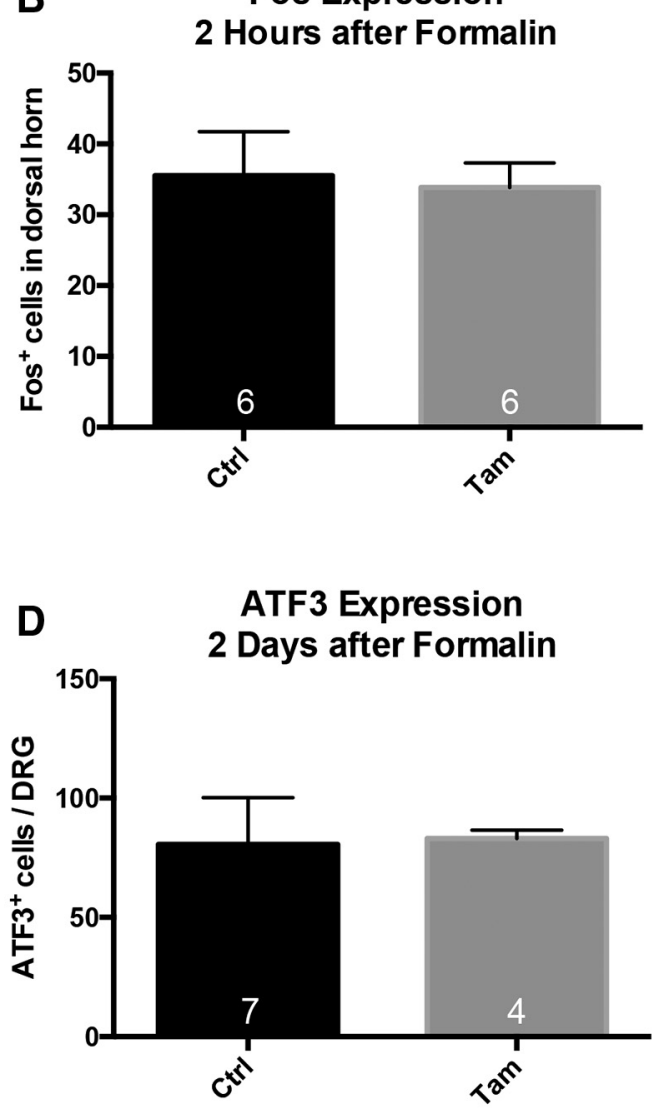

Figure 8. Formalin-induced expression of spinal cord Fos and primary afferent ATF3 in male BDNF-cKO mice. $\boldsymbol{A}, \boldsymbol{B}$, Two hours after formalin, control (Ctrl) and tamoxifen (Tam)-treated (cKO) mice showed a comparable increase of Fos immunoreactivity in the spinal dorsal horn ipsilateral to the injected paw. $\boldsymbol{C}, \boldsymbol{D}$. Both groups also showed equivalent ATF3 induction in L4/5 DRGs $2 \mathrm{~d}$ after the formalin injection, consistent with formalin producing peripheral axotomy. Data are mean \pm SEM. Statistical significance was determined by Student's $t$ test. Numbers of animals are indicated on graphs. Scale bars $=50 \mu \mathrm{m}(\boldsymbol{A})$ and $100 \mu \mathrm{m}(\boldsymbol{C})$.

(Sikandar et al., 2018), they reported opposite results, namely decreased, responsiveness in the hot plate test and a reduction in mechanical hypersensitivity in a neuropathic pain model. Although the authors did not address these discrepancies, clearly the timing (adult vs embryonic) and extent of the BDNF deletion (partial in the Nav1.8-Cre cross vs complete in the Advillin-CreER cross) appears to be critical. Furthermore, in the NaV1.8 knock-out study, BDNF was not eliminated from all DRG neurons (Zhao et al., 2006), omitting some that have been implicated in mechanical allodynia after nerve injury (Seal et al., 2009; Abraira and Ginty, 2013). And, of course, compensatory molecular reorganization in the setting of developmental BDNF (NaV1.8-mediated) deletion could also have contributed to the differences in the observed phenotypes. Most surprising, however, is that using the same deletion (adult) protocol as (Sikandar et al., 2018), we only detected a significant effect of BDNF knock-out on the second phase of the formalin test, but in contrast to results from that report, we only observed the deficit in male mice.

In general, activity in the first phase of the formalin test is thought to drive dorsal horn central sensitization, which then catalyzes the second phase (Latremoliere and Woolf,
2009) Consistent with this view, BDNF increases the excitability of sensory neurons (Chen et al., 2014) and superficial dorsal horn neurons (Kerr et al., 1999; Garraway et al., 2003; Hildebrand et al., 2016) and leads to phosphorylation of spinal NMDA receptors (Slack and Thompson, 2002; Slack et al., 2004; Liu et al., 2015; however, see Pezet et al., 2002). These observations, when viewed in light of our results, suggest that BDNF may be necessary for spinal sensitization in the formalin model for male, but not female mice. Indeed, there is precedent for sexual dimorphism in BDNF signaling. For example, TrkB expression is regulated by androgens (Liu et al., 2012). As the formalin test is thought to model postsurgical pain, the sexual dimorphism we observed could have particular clinical relevance.

Overall, however, we found few pain or itch phenotypes after deleting BDNF selectively from primary afferent neurons. This is in stark contrast to numerous behavioral reports that found large behavioral effects after inhibiting BDNF/TrkB signaling, including studies from our own laboratory (Wang et al., 2009), where we used systemic pharmacological blockage of TrkB rather than selective sensory neuron deletion of BDNF. In that study we demonstrated that TrkB-signaling is necessary for behavioral 

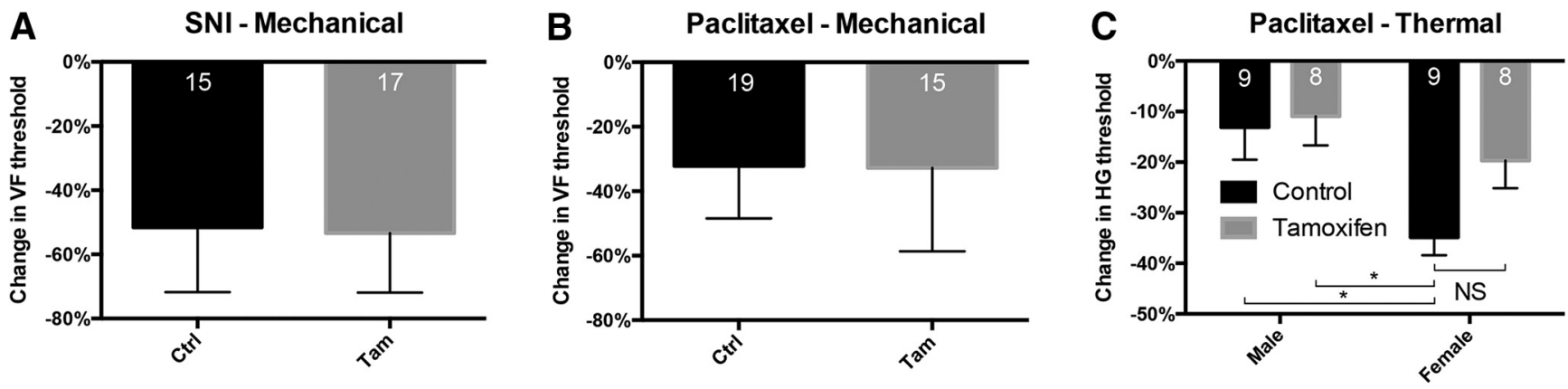

D CFA - Mechanical

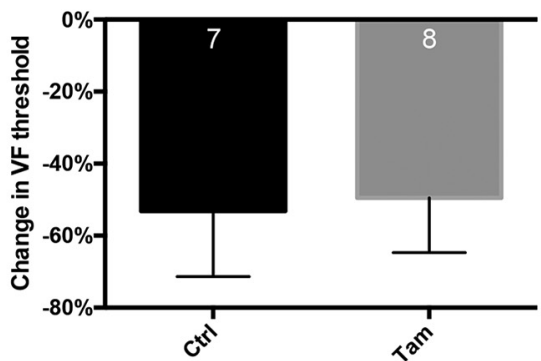

E CFA - Thermal

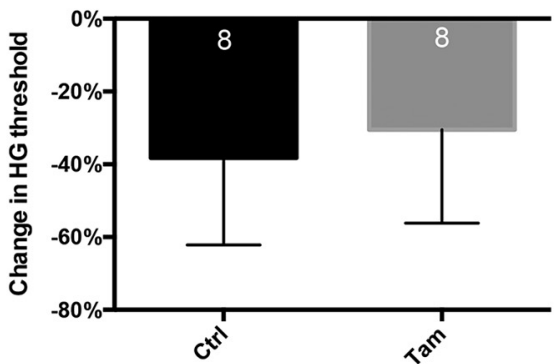

Figure 9. Tissue and nerve injury-induced hypersensitivity in BDNF-cKO mice. $\boldsymbol{A}$, Tamoxifen-treated cKO animals developed normal mechanical allodynia one week after SNI. B, Mechanical allodynia also did not differ between tamoxifen- and corn oil-treated mice in a paclitaxel-induced chemotherapy model of neuropathic pain. $\boldsymbol{C}$, Unexpectedly, female control mice developed greater thermal hypersensitivity $12 \mathrm{~d}$ after paclitaxel compared to male groups. While this hypersensitivity decreased after tamoxifen-treatment, it did not do so significantly $(\boldsymbol{p}>0.05)$. Mechanical allodynia $(\boldsymbol{D})$ and thermal hypersensitivity $(\boldsymbol{E})$ also did not differ between BDNF cKO and control mice $3 \mathrm{~d}$ after CFA injection. Data are mean \pm SEM. For $\boldsymbol{A}, \boldsymbol{B}, \boldsymbol{D}, \boldsymbol{E}$, statistical significance was determined by Student's $t$ test. For $\boldsymbol{C}$, statistical significance was determined by two-way ANOVA with Bonferroni correction for multiple comparisons; $* p<0.05$. Numbers of animals are indicated on graphs.

sensitization after nerve injury, which agreed with many other studies that applied BDNF peripherally or administered intrathecal BDNF or TrkB scavengers (Shu et al., 1999; Thompson et al., 1999; Fukuoka et al., 2001; Groth and Aanonsen, 2002; Coull et al., 2005; Bao et al., 2014). Reconciling these findings with our new observations raises several possibilities. First, rather than these phenotypes deriving from sensory neurons, pain- and itchrelevant BDNF might originate in the spinal cord or from descending fibers from the brain (for example, see Hsieh et al., 2016). Importantly, in contrast with an earlier report that found no BDNF expression in neonatal mouse spinal cord (Heppenstall and Lewin, 2001), our in situ analysis in the adult revealed very extensive expression in spinal cord neurons. However, in agreement with a recent transcriptome analysis (Zhang et al., 2014), we could not demonstrate expression of BDNF in microglia, even in the fate map analysis. This result was surprising and suggests that the BDNF contribution to spinal cord processing of pain messages is, in fact, neuron derived. Second, NT$4 / 5$, which also binds selectively to TrkB, might regulate aspects of pain processing widely attributed to BDNF. Third, conditional BDNF knock-out from sensory neurons, although generally considered more appropriate than embryonic deletion, could still produce compensatory changes that influence behavior. Nevertheless, its predominant expression in myelinated sensory neurons and limited contribution to pain and itch suggest that future studies should investigate primary afferent-derived BDNF as well as TrkB signaling in the context of low-threshold mechanotransduction.

\section{References}

Abraira VE, Ginty DD (2013) The sensory neurons of touch. Neuron 79:618-639. CrossRef Medline

Bao Y, Hou W, Liu R, Gao Y, Kong X, Yang L, Shi Z, Li W, Zheng H, Jiang S, Li C, Qin Y, Hua B (2014) PAR2-mediated upregulation of BDNF contributes to central sensitization in bone cancer pain. Mol Pain 10:28. CrossRef Medline

Barakat-Walter I (1996) Brain-derived neurotrophic factor-like immunoreactivity is localized mainly in small sensory neurons of rat dorsal root ganglia. J Neurosci Methods 68:281-288. Medline

Bráz JM, Sharif-Naeini R, Vogt D, Kriegstein A, Alvarez-Buylla A, Rubenstein JL, Basbaum Al (2012) Forebrain GABAergic neuron precursors integrate into adult spinal cord and reduce injuryinduced neuropathic pain. Neuron, 74:663-675. CrossRef Medline

Betley JN, Wright CV, Kawaguchi Y, Erdélyi F ,Szabó G, Jessell TM, Kaltschmidt JA (2009) Stringent specificity in the construction of a GABAergic presynaptic inhibitory circuit. Cell 139:161-174. CrossRef

Binder DK, Scharfman HE (2004) Brain-derived neurotrophic factor. Growth Factors 22:123-131. Medline

Cao XH, Chen SR, Li L, Pan HL (2012) Nerve injury increases brain-derived neurotrophic factor levels to suppress BK channel activity in primary sensory neurons. J Neurochem 121:944-953. CrossRef

Cao YQ, Mantyh PW, Carlson EJ, Gillespie AM, Epstein CJ, Basbaum Al (1998) Primary afferent tachykinins are required to experience moderate to intense pain. Nature 392:390-394. CrossRef

Chen W, Walwyn W, Ennes HS, Kim H, McRoberts JA, Marvizón JC (2014) BDNF released during neuropathic pain potentiates NMDA 
receptors in primary afferent terminals. Eur J Neurosci 39:14391454. CrossRef

Cho HJ, Kim JK, Zhou XF, Rush RA (1997) Increased brain-derived neurotrophic factor immunoreactivity in rat dorsal root ganglia and spinal cord following peripheral inflammation. Brain Res 764:269272. CrossRef

Conner JM, Lauterborn JC, Yan Q, Gall CM, Varon S (1997) Distribution of brain-derived neurotrophic factor (BDNF) protein and mRNA in the normal adult rat CNS: evidence for anterograde axonal transport. J Neurosci 17:2295-2313. CrossRef

Coull JA, Beggs S, Boudreau D, Boivin D, Tsuda M, Inoue K, Gravel C, Salter MW, De Koninck Y (2005) BDNF from microglia causes the shift in neuronal anion gradient underlying neuropathic pain. Nature 438:1017-1021. CrossRef

Dhaka A, Earley TJ, Watson J, Patapoutian A (2008) Visualizing cold spots: TRPM8-expressing sensory neurons and their projections. J Neurosci 28:566-575. CrossRef Medline

Dhandapani R, Arokiaraj CM, Taberner FJ, Pacifico P, Raja S, Nocchi L, Portulano C, Franciosa F, Maffei M, Hussain AF, de Castro Reis F, Reymond L, Perlas E, Garcovich S, Barth S, Johnsson K, Lechner SG, Heppenstall PA (2018) Control of mechanical pain hypersensitivity in mice through ligand-targeted photoablation of TrkB-positive sensory neurons. Nat Commun 9 1640. CrossRef

Ernfors P, Lee KF, Jaenisch R (1994) Mice lacking brain-derived neurotrophic factor develop with sensory deficits. Nature 368:147150. CrossRef

Fukuoka T, Kondo E, Dai Y, Hashimoto N, Noguchi K (2001) Brainderived neurotrophic factor increases in the uninjured dorsal root ganglion neurons in selective spinal nerve ligation model. J Neurosci 21:4891-4900. CrossRef

Garraway SM, Petruska JC, Mendell LM (2003) BDNF sensitizes the response of lamina II neurons to high threshold primary afferent inputs. Eur J Neurosci 18:2467-2476. Medline

Gorski JA, Zeiler SR, Tamowski S, Jones KR (2003) Brain-derived neurotrophic factor is required for the maintenance of cortical dendrites. J Neurosci 23:6856-6865. CrossRef

Groth R, Aanonsen L (2002) Spinal brain-derived neurotrophic factor (BDNF) produces hyperalgesia in normal mice while antisense directed against either BDNF or trkB, prevent inflammationinduced hyperalgesia. Pain 100:171-181. Medline

Heppenstall PA, Lewin GR (2001) BDNF but not NT-4 is required for normal flexion reflex plasticity and function. Proc Natl Acad Sci USA 98:8107-8112. CrossRef Medline

Hildebrand ME, Xu J, Dedek A, Li Y, Sengar AS, Beggs S, Lombroso PJ, Salter MW (2016) Potentiation of synaptic GluN2B NMDAR currents by fyn kinase is gated through BDNF-mediated disinhibition in spinal pain processing. Cell Rep 17:2753-2765. CrossRef

Hsieh MC, Lai CY, Ho YC, Wang HH, Cheng JK, Chau YP, Peng HY (2016) Tet1-dependent epigenetic modification of BDNF expression in dorsal horn neurons mediates neuropathic pain in rats. Sci Rep 6:37411. CrossRef

Kerr BJ, Bradbury EJ, Bennett DL, Trivedi PM, Dassan P, French J, Shelton DB, McMahon SB, Thompson SW (1999) Brain-derived neurotrophic factor modulates nociceptive sensory inputs and NMDA-evoked responses in the rat spinal cord. J Neurosci 19: 5138-5148. CrossRef

Latremoliere A, Woolf CJ (2009) Central sensitization: a generator of pain hypersensitivity by central neural plasticity. J Pain 10:895926. CrossRef Medline

Lau J, Minett MS, Zhao J, Dennehy U, Wang F, Wood JN, Bogdanov YD (2011) Temporal control of gene deletion in sensory ganglia using a tamoxifen-inducible advillin-Cre-ERT2 recombinase mouse. Mol Pain 7:100. CrossRef

Lin YT, Ro LS, Wang HL, Chen JC (2011) Up-regulation of dorsal root ganglia BDNF and trkB receptor in inflammatory pain: an in vivo and in vitro study. J Neuroinflammation 8:126. CrossRef Medline

Liu M, Kay JC, Shen S, Qiao LY (2015) Endogenous BDNF augments NMDA receptor phosphorylation in the spinal cord via PLC $\gamma, \operatorname{PKC}$, and PI3K/Akt pathways during colitis. J Neuroinflammation 12: 151. CrossRef Medline
Liu Y, Rutlin M, Huang S, Barrick CA, Wang F, Jones KR, Tessarollo L, Ginty DD (2012) Sexually dimorphic BDNF signaling directs sensory innervation of the mammary gland. Science 338:13571360. CrossRef

Luo XG, Rush RA, Zhou XF (2001) Ultrastructural localization of brain-derived neurotrophic factor in rat primary sensory neurons. Neurosci Res 39:377-384. CrossRef

Michael GJ, Averill S, Nitkunan A, Rattray M, Bennett DL, Yan Q, Priestley JV (1997) Nerve growth factor treatment increases brainderived neurotrophic factor selectively in TrkA-expressing dorsal root ganglion cells and in their central terminations within the spinal cord. J Neurosci 17:8476-8490. CrossRef

Obata K, Yamanaka H, Kobayashi K, Dai Y, Mizushima T, Katsura H, Fukuoka T, Tokunaga A, Noguchi K (2006) The effect of site and type of nerve injury on the expression of brain-derived neurotrophic factor in the dorsal root ganglion and on neuropathic pain behavior. Neuroscience 137:961-970. CrossRef

Pezet S, Malcangio M, McMahon SB (2002) BDNF: a neuromodulator in nociceptive pathways? Brain Res Brain Res Rev 40:240249. Medline

Salio C, Ferrini F (2016) BDNF and GDNF expression in discrete populations of nociceptors. Ann Anat 207:55-61. CrossRef Medline

Seal RP, Wang X, Guan Y, Raja SN, Woodbury CJ, Basbaum Al, Edwards RH (2009) Injury-induced mechanical hypersensitivity requires C-low threshold mechanoreceptors. Nature 462:651-655. CrossRef

Shields SD, Cavanaugh DJ, Lee H, Anderson DJ, Basbaum AI (2010) Pain behavior in the formalin test persists after ablation of the great majority of C-fiber nociceptors. Pain 151:422-429. CrossRef Medline

Shields SD, Eckert WA 3rd, Basbaum Al (2003) Spared nerve injury model of neuropathic pain in the mouse: a behavioral and anatomic analysis. J Pain 4:465-470. Medline

Shu XQ, Llinas A, Mendell LM (1999) Effects of trkB and trkC neurotrophin receptor agonists on thermal nociception: a behavioral and electrophysiological study. Pain 80:463-470. CrossRef

Sikandar S, Minett MS, Millet Q, Santana-Varela S, Lau J, Wood JN, Zhao J (2018) Brain-derived neurotrophic factor derived from sensory neurons plays a critical role in chronic pain. Brain 141:10281039. CrossRef

Slack SE, Thompson SW (2002) Brain-derived neurotrophic factor induces NMDA receptor 1 phosphorylation in rat spinal cord. Neuroreport 13:1967-1970. Medline

Slack SE, Pezet S, McMahon SB, Thompson SW, Malcangio M (2004) Brain-derived neurotrophic factor induces NMDA receptor subunit one phosphorylation via ERK and PKC in the rat spinal cord. Eur J Neurosci 20:1769-1778. CrossRef

Takashima Y, Ma L, McKemy DD (2010) The development of peripheral cold neural circuits based on TRPM8 expression. Neuroscience 169:828-842. CrossRef Medline

Taylor BK, Peterson MA, Basbaum Al (1997) Early nociceptive events influence the temporal profile, but not the magnitude, of the tonic response to subcutaneous formalin: effects with remifentanil. J Pharmacol Exp Ther 280:876-883. Medline

Thompson SW, Bennett DL, Kerr BJ, Bradbury EJ, McMahon SB (1999) Brain-derived neurotrophic factor is an endogenous modulator of nociceptive responses in the spinal cord. Proc Natl Acad Sci USA 96:7714-7718. CrossRef

Wang X, Ratnam J, Zou B, England PM, Basbaum AI (2009) TrkB signaling is required for both the induction and maintenance of tissue and nerve injury-induced persistent pain. J Neurosci 29: 5508-5515. CrossRef Medline

Wang X, Zhang J, Eberhart D, Urban R, Meda K, Solorzano C, Yamanaka H, Rice D, Basbaum Al (2013) Excitatory superficial dorsal horn interneurons are functionally heterogeneous and required for the full behavioral expression of pain and itch. Neuron 78:312-324. CrossRef

Wetmore C, Olson L (1995) Neuronal and nonneuronal expression of neurotrophins and their receptors in sensory and sympathetic 
ganglia suggest new intercellular trophic interactions. J Comp Neurol 353:143-159. CrossRef

Xu B, Goulding EH, Zang K, Cepoi D, Cone RD, Jones KR, Tecott LH, Reichardt LF (2003) Brain-derived neurotrophic factor regulates energy balance downstream of melanocortin-4 receptor. Nat Neurosci 6:736-742. CrossRef

Zeitz KP, Giese KP, Silva AJ, Basbaum Al (2004) The contribution of autophosphorylated alpha-calcium-calmodulin kinase II to injury-induced persistent pain. Neuroscience 128:889-898. CrossRef

Zhang Y, Chen K, Sloan SA, Bennett ML, Scholze AR, O'Keeffe S, Phatnani HP, Guarnieri P, Caneda C, Ruderisch N, Deng S, Liddelow SA, Zhang C, Daneman R, Maniatis T, Barres BA, Wu JO
(2014) An RNA-sequencing transcriptome and splicing database of glia, neurons, and vascular cells of the cerebral cortex. J Neurosci 34:11929-11947. CrossRef

Zhao J, Seereeram A, Nassar MA, Levato A, Pezet S, Hathaway G, Morenilla-Palao C, Stirling C, Fitzgerald M, McMahon SB, Rios M, Wood JN; London Pain Consortium (2006) Nociceptor-derived brain-derived neurotrophic factor regulates acute and inflammatory but not neuropathic pain. Mol Cell Neurosci 31:539-548. CrossRef

Zhou XF, Chie ET, Deng YS, Zhong JH, Xue Q, Rush RA, Xian CJ (1999) Injured primary sensory neurons switch phenotype for brain-derived neurotrophic factor in the rat. Neuroscience 92:841853. CrossRef 